Original Research Article

\title{
Efficacy of ciclesonide, budesonide and beclomethasone dipropionate in moderate persistent bronchial asthma: a comparative study
}

\author{
Mohana Rupa L. ${ }^{1}{ }^{*}$, Maduram A. ${ }^{2}$, Jagan Nadipelly ${ }^{3}$
}

${ }^{1}$ Department of Pharmacology, Maheshwara Medical College and Hospital, Chitkul, Isnapur, Patancheru, Telangana, India ${ }^{2}$ Department of Pharmacology, Sri Sathya Sai Medical College and Research Institute,

Tiruporur, Guduvancherry, Ammapettai, Sembakkam, Tamil Nadu, India ${ }^{3}$ Department of Pharmacology College of Medicine, Texila American University, Georgetown, Guyana, South America

Received: 23 July 2019

Revised: 10 September 2019

Accepted: 11 September 2019

*Correspondence to:

Dr. Mohana Rupa L.,

Email: drmohanarupa @gmail.com.

Copyright: (C) the author(s), publisher and licensee Medip Academy. This is an openaccess article distributed under the terms of the Creative Commons Attribution NonCommercial License, which permits unrestricted noncommercial use, distribution, and reproduction in any medium, provided the original work is properly cited.

\begin{abstract}
Background: The objective of the present study was to compare the efficacy and adverse effects of ciclesonide with that of budesonide and beclomethasone dipropionate in moderate persistent cases of bronchial asthma.

Methods: This was an open label, randomized parallel group study done in Government General and Chest Hospital, Hyderabad for a period of 12 weeks. Each group had 20 patients. Group A was given ciclesonide inhalational therapy $160 \mathrm{mcg}$ once daily. Group B was given budesonide inhalational therapy 400 mcg twice daily. Group $\mathrm{C}$ was given beclomethasone dipropionate inhalational therapy 400 mcg twice daily.

Results: Symptomatic improvement was observed in all three groups. At end point, mean $\mathrm{FEV}_{1}$ in ciclesonide treatment group improved by $23.84 \%$ compared with $15.24 \%$ in budesonide and $12.93 \%$ in beclomethasone treatment groups. At end point, mean FVC value in ciclesonide treatment group improved by $6.44 \%$ compared with $1.5 \%$ in budesonide and $1.06 \%$ in beclomethasone groups. Mean $\mathrm{FEV}_{1} / \mathrm{FVC}$ also improved by $16.56 \%$ in ciclesonide group compared with $13.68 \%$ in budesonide and $11.93 \%$ in beclomethasone groups. No adverse effects were reported in any of the treatment groups.

Conclusions: This study showed that ciclesonide is superior to budesonide and beclomethasone in improving lung function, decreasing symptoms and need for rescue medication in moderate persistent asthma.
\end{abstract}

Keywords: Ciclesonide, Budesonide, Beclomethasone, Moderate persistent asthma

inflammatory processes in order to achieve effective asthma control. At present inhaled corticosteroids are the most commonly used anti-inflammatory drugs in asthma control and according to national and international guidelines, they are recommended as the first-line agents for persistent asthma, either alone or combined with longacting beta-agonists. ${ }^{2,3}$ According to National Asthma 
Education and Prevention Program, moderate persistent asthma is characterized by daily symptoms. ${ }^{4}$ Exacerbations affect activity. Night time symptoms $>1$ time a week, FEV1or PEF $>60-<80 \%$ predicted, PEF variability $>30 \%$. Inhaled corticosteroids are the mainstay of therapy in asthma, but local and systemic side effects and adherence remain a concern.

This study was done to compare the clinical efficacy and adverse effects of three different inhaled glucocorticoids namely ciclesonide, budesonide and beclomethasone dipropionate in moderate persistent cases of bronchial asthma.

\section{METHODS}

This is an open label, randomized parallel group study done in Government General and Chest Hospital, Hyderabad for a period of 12 weeks from May 2018 to August 2018. The study design was approved by Institutional ethics committee and the written informed consent is obtained from patients who participated in the study.

\section{Inclusion criteria}

Patients in the age group of 20-55 years of either sex with a history of episodic wheezing, difficulty in breathing, chest tightness and cough with or without expectoration and patients having nocturnal symptoms and family history of asthma were included in the study.

\section{Exclusion criteria}

Pregnant and lactating women, smokers and patients with symptoms related to occupation, patients who were already on steroid treatment for bronchial asthma, patients with history of pulmonary tuberculosis, chronic obstructive pulmonary disease, recurrent pulmonary emboli, carcinoid tumour, tropical eosinophilia, diabetes mellitus, hypertension, chronic renal failure, bronchogenic carcinoma and suspected malignancy anywhere in the body were excluded from the study.

After history was taken, a detailed clinical examination was done. These are complete blood picture, sputum examination, random blood sugar, serum creatinine, chest $\mathrm{X}$-ray posteroanterior view, electrocardiography.

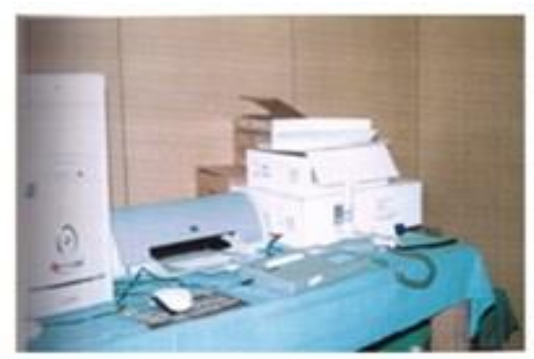

Figure 1: Microloop or microlab spirometer.
Microloop or microlab spirometer (Figure 1, 2) was used to measure pulmonary function tests; forced vital capacity (FVC), forced expiratory volume in one second $\left(\mathrm{FEV}_{1}\right)$, forced expiratory ratio $\left(\mathrm{FEV}_{1} / \mathrm{FVC}\right)$. A written informed consent was obtained from each patient.

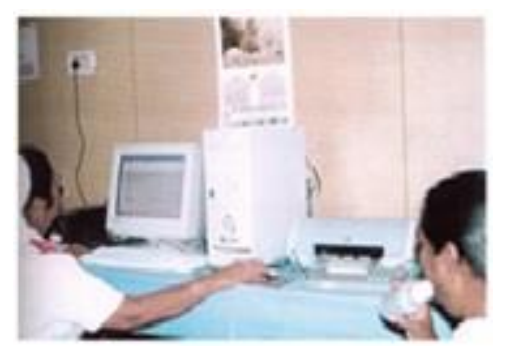

Figure 2: Patient undergoing pulmonary function test.

The total number of patients was randomized into 3 groups. Each group had 20 patients.

Group A: Ciclesonide inhalational therapy $160 \mathrm{mcg}$ once daily.

Group B: Budesonide inhalational therapy $400 \mathrm{mcg}$ twice daily.

Group C: Beclomethasone dipropionate inhalational therapy $400 \mathrm{mcg}$ twice daily.

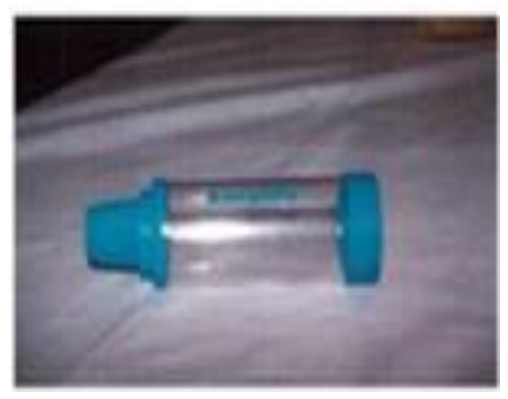

Figure 3: Spacer.

The patients were advised to take salbutamol inhalation (100 mcg per puff) as needed. Metered dose inhaler with spacer (Figure 3) was used for taking medication. Patients were shown inhalation technique with spacers. They were advised to rinse their mouth after each inhalation. They were followed up once in every two weeks till a period of 12 weeks. At each visit, they were clinically assessed and pulmonary function tests were done. Scoring was done for cough, wheeze, breathlessness and severity of nocturnal symptoms (0- no symptoms, 1- mild, 2- moderate, 3- severe). ${ }^{5,6}$

Score for frequency of use of rescue medication $(0-<2$ puffs/week, 1- <2 puffs/day, 2- 2 to 4 puffs/day, 3- >4 puffs/day). ${ }^{6}$

At each visit, patients were assessed for any adverse effects. 


\section{Statistical analysis}

Data is presented in mean \pm SEM and percentages as applicable. ANOVA was applied for comparison of the treatment groups. Unpaired student's t-test was applied to test the level of significance. $\mathrm{P}<0.05$ was considered as the level of significance.

\section{RESULTS}

Of the 60 patients who enrolled in the study, 20 were assigned to each group (Table 1) of the three treatment options (ciclesonide $160 \mathrm{mcg}$ once daily, $\mathrm{n}=20$; budesonide $400 \mathrm{mcg}$ twice daily, $\mathrm{n}=20$ and beclomethasone dipropionate $400 \mathrm{mcg}$ twice daily, $\mathrm{n}=20$ ). Improvement of symptoms in patients with mild persistent asthma was significantly more in ciclesonide group when compare to other two treatments (Figure 4) and use of rescue medication was also decreased in ciclesonide group when compare to other two treatments (Figure 5). The $\mathrm{FEV}_{1}, \mathrm{FVC}, \mathrm{FEV}_{1} / \mathrm{FVC}$ improved with respect to baseline. A significant effect was observed in favour of ciclesonide compared with beclomethasone dipropionate and budesonide (Figure 6). At end point, mean $\mathrm{FEV}_{1}$ in ciclesonide group improved by 0.521 (23.84\%) compared with improvements of $0.31 \quad 1$ $(15.24 \%)$ in budesonide $(\mathrm{p}<0.001)$ and $0.251(12.93 \%)$ in beclomethasone dipropionate groups $(\mathrm{p}<0.001)$. At end point, mean FVC value in ciclesonide group improved by $6.44 \%$ compared with improvements of $1.5 \%$ in budesonide $(\mathrm{p}<0.001)$ and $1.06 \%$ in beclomethasone dipropionate groups $(\mathrm{p}<0.001)$. Mean $\mathrm{FEV}_{1} / \mathrm{FVC}$ also improved by $16.56 \%$ compared with $13.68 \%$ in budesonide $(\mathrm{p}<0.05)$ and $11.93 \%$ in beclomethasone groups $(\mathrm{p}<0.01)$. No adverse effects were reported in any of the treatment groups.

Table 1: Demographic data of patients with mild persistent asthma.

\begin{tabular}{|lccc|}
\hline Drug & No. of men & No. of women & Mean age $( \pm$ SEM) (in years) \\
\hline Ciclesonide (n=20) & 10 & 10 & $35.2 \pm 1.4$ \\
\hline Budesonide $(\mathbf{n = 2 0})$ & 10 & 10 & $32.9 \pm 1.1$ \\
\hline Beclomethasone dipropionate $(\mathbf{n = 2 0})$ & 10 & 10 & $33.4 \pm 1.2$ \\
\hline
\end{tabular}

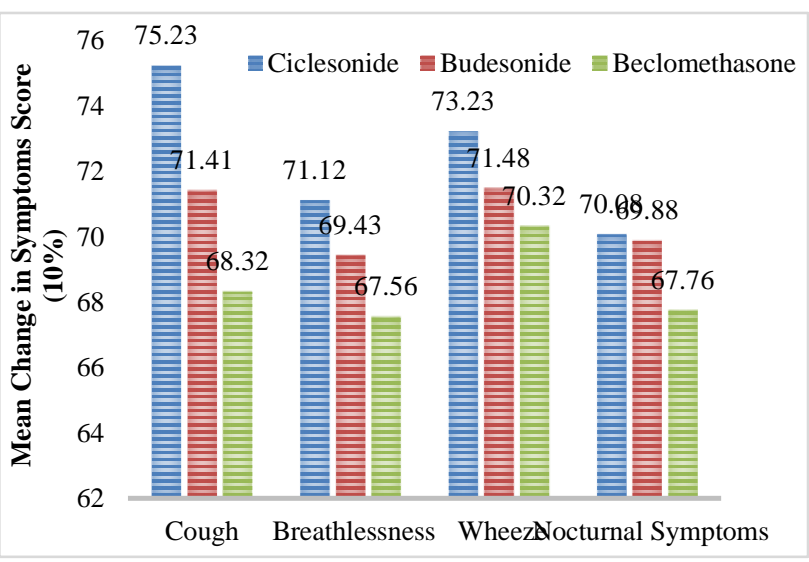

Figure 4: Improvement of symptoms in patients with moderate persistent asthma.

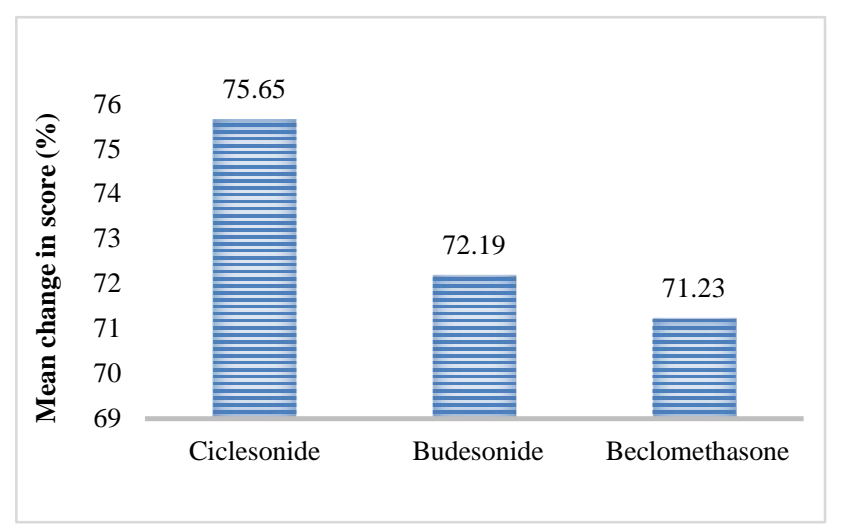

Figure 5: Reduction in frequency of rescue medication in patients with moderate persistent asthma.

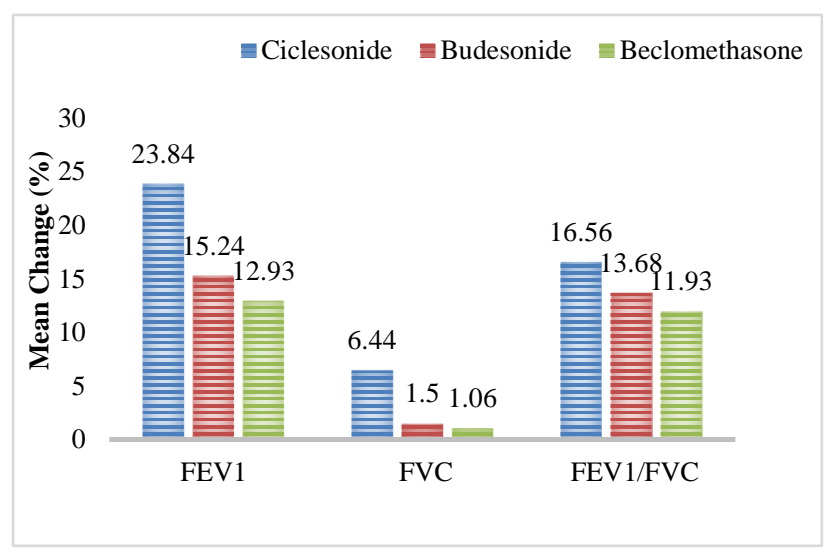

Figure 6: Assessment of FEV1, FVC, $\mathrm{FEV}_{1} / \mathrm{FVC}$ in patients with moderate persistent asthma.

\section{DISCUSSION}

This study evaluated the efficacy of commonly prescribed doses of inhalational steroids in moderate persistent asthma. Ciclesonide $160 \mathrm{mcg}$ once daily, budesonide $400 \mathrm{mcg}$ twice daily, beclomethasone dipropionate $400 \mathrm{mcg}$ twice daily were given. Our findings showed that both agents improved lung function and led to asthma control during a prolonged treatment period of 12 weeks.

Ciclesonide treatment produced significantly greater improvements in lung function $\left(\mathrm{FEV}_{1}, \mathrm{FVC}\right.$ and $\mathrm{FEV}_{1} / \mathrm{FVC}$ ) than budesonide and beclomethasone dipropionate. Patient compliance was good, which was $100 \%$ in all the groups. 
Dahl et al compared ciclesonide at a daily dose of 220 mcg with beclomethasone dipropionate at a daily dose of $400 \mathrm{mcg}^{7}{ }^{7}$ They found that ciclesonide is more efficacious than beclomethasone dipropionate in the treatment of mild to moderate bronchial asthma.

Chiu et al in a study compared ciclesonide $160 \mathrm{mcg}$ once daily with budesonide $400 \mathrm{mcg}$ per day. ${ }^{8} \mathrm{He}$ reported that ciclesonide produced significant improvement in asthma symptoms. Similar improvement in pulmonary function tests was observed in both the groups. Beclomethasone dipropionate was compared with budesonide over a wide range of doses in previous studies. These studies showed that the two drugs have similar effects on asthma control. Present study supports the findings observed in the above studies. No adverse effects were reported in any of the treatment groups during study period. Local adverse effects like oral candidiasis was not observed in any of the treatment groups. This might be due to the use of spacer and thorough rinsing of mouth after each inhalation.

\section{CONCLUSION}

Ciclesonide is superior to budesonide and beclomethasone dipropionate in improving lung function, decreasing symptoms and need for rescue medication in moderate persistent asthma. Patient compliance was good with all the three drugs. All the three drugs were well tolerated at the doses used in this study.

Funding: No funding sources

Conflict of interest: None declared

Ethical approval: The study was approved by the Institutional Ethics Committee

\section{REFERENCES}

1. Masoli M, Fabian D, Holt S, Beasley R, Global initiative for asthma (GINA) Program. The global burden of asthma: executive summary of the GINA Dissemination Committee report. Allergy. 2004;59(5):469-78.

2. Global Initiative for Asthma. Global strategy for asthma management and prevention, 2009. Available at: http://www.ginasthma.com. Accessed on 20 March 2019.

3. National Heart Lung and Blood Institute Expert panel report 3 (EPR3): guidelines for the diagnosis and management of asthma, 2007. Available at: http://www.nhlbi.nih.gov. Accessed on 20 March 2019.

4. Raphael GD, Lanier RQ, Baker J, Edwards L, Richard K, Lincourt WR. A comparison of multiple doses of ciclesonide and beclomethasone dipropionate in subjects with persistent asthma. J Allergy Clin Immunol. 1999;103:796-803.

5. Louis R, Lau LCK, Bron AO, Rodaan AC, Radermecker M, Djukanovic R. The relationship between airways inflammation and asthma severity. Am J Respir Crit Care Med. 2000;161:9-16.

6. Asthma Allergy and Airway Research Center. Information for Health Care Professionals. Asthma assessment. Available at: http://www.upmc.Edu /AAARC/professionals.htm. Accessed on $20 \mathrm{March}$ 2019.

7. Dahl R. Ciclesonide for the treatment of asthma. Ther Clin Risk Manag. 2006;2(1):25-38.

8. Chiu KC, Chou YL, Hsu JY, Lin MS, Lin CH, Chou $\mathrm{PC}$, et al. Comparison of the efficacy of ciclesonide with that of budesonide in mild to moderate asthma patients after step-down therapy: a randomised parallel-group study. NPJ Prim Care Respir Med. 2014;24:14010.

Cite this article as: Rupa ML, Maduram A,

Nadipelly J. Efficacy of ciclesonide, budesonide and beclomethasone dipropionate in moderate persistent bronchial asthma: a comparative study. Int J Basic Clin Pharmacol 2019;8:2267-70. 